\title{
Previous utilization of service does not improve timely booking in antenatal care: Cross sectional study on timing of antenatal care booking at public health facilities in Addis Ababa
}

\author{
Alemayehu Tariku ${ }^{1}$ Yilma Melkamu² Zewditu Kebede ${ }^{3}$
}

\begin{abstract}
Background: Antenatal care is more beneficial in preventing adverse pregnancy outcomes when it is sought early in pregnancy. However, existing evidence from developing countries including Ethiopia indicate that few women seek antenatal care at early stage of their pregnancy.

Objective: The objective of this study was to assess the timing of ANC booking and impact of previous antenatal care utilization on timing of first antenatal care booking in Addis Ababa governmental health institutions.

Methods: A cross sectional study was conducted to collect data from 630 pregnant women who were attending antenatal care service at 10 governmental health centers in Addis Ababa from March 1 to 30, 2008.

Results: Past experience on antenatal care service utilization did not come out as a predictor for timely booking of antenatal care $(\mathrm{OR}=1.40,95 \% \mathrm{CI}: 0.91,2.15)$. Multivariate analysis revealed that respondents who received advice on recommended time of booking, their pregnancy was planned and first pregnancy, were more likely to book timely compared to others $(\mathrm{AOR}=10.10,95 \% \mathrm{CI}: 4.54,22.40 ; \mathrm{AOR}=1.87,95 \% \mathrm{CI}: 1.11,3.23$; $(\mathrm{AOR}=1.86,95 \% \mathrm{CI}: 1.01$, 3.44) respectively.

Conclusions: Past utilization of antenatal care service did not come as a predictor for timely booking of the service, provided that advice on timely booking is the main factor. In order to improve the situation, strengthening of focused antenatal care, availing of clear service delivery guidelines and training of service providers are important. [Ethiop. J. Health Dev. 2010;24(3):226-233]
\end{abstract}

\section{Introduction}

Antenatal Care (ANC) is a type of care given for women during pregnancy and it is one of the pillars of maternal health service. The goal of ANC is to prevent health problems of pregnant women and to ensure that each newborn child has a good start (1).

The new WHO antenatal care model recommends that first ANC visit should occur within the first trimester of pregnancy. The first visit offers an opportunity to establish baseline information on the general wellbeing of the mother and the pregnancy. It also helps the expectant mothers assess personally the services provided in the facility and build up their impression about the establishment (2).

Pregnant women should be offered screening for HIV infection early in ANC since appropriate ANC interventions can reduce mother-to-child transmission of HIV infection. These enable the expectant mother to decide whether to share her HIV status with anyone and, if so, with whom. It also helps her benefit from antiretroviral therapy where applicable and understand infant feeding options and choose that which is best in her circumstances. Moreover the intervention help the woman learn more about HIV infection and its implications for her health, access support groups and health services that promote positive living and make choices about sexual behavior and future fertility (2).

Screening for syphilis should be offered to all pregnant women at an early stage. In pregnant women with untreated syphilis, $70 \%$ to $100 \%$ of infants will be infected and one third will be stillborn (3).

Pregnant women should be offered iron and folic acid supplementation early in pregnancy. Supplementation of pregnant women and those intending to become pregnant and who are at risk of nutritional deficiency with folic acid, before conception and up to 12 weeks of gestation, reduces the risk of having a baby with neural tube defects such as anencephaly and spina bifida (2-4).

The majority of pregnant women with nausea and vomiting report symptoms within 8 weeks of their last menstrual period with over one third of them reporting symptoms within 4 weeks of their last menstrual period. The severity of nausea and vomiting varies greatly among pregnant women. Hyperemesis gravidarum is a condition in which an intractable vomiting occurs in early pregnancy leading to fluid and electrolyte disturbances and nutritional deficiency in the pregnant women. Even though the condition is rare, unless the pregnant mothers are monitored and provided with basic

ALKAN University College, E-mail tarikualemayehu2000@yaoo.com, Addis Ababa, Ethiopia;

${ }^{2}$ IPPF Africa Regional Office, E-mail yilmamelkamu@yahoo.com, Nairobi, Kenya;

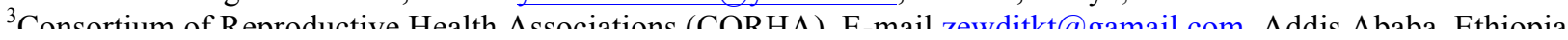


information during this period, they may experience to use un-prescribed possible teratogenic drugs which may affect the growing embryos and affect the outcome of the fetus (4).

While there are potential benefits to be gained from some of the elements of ANC, and these benefits may be most significant in developing countries where maternal morbidity and mortality levels are high most pregnant women presenting for ANC in Sub-Saharan Africa countries are most likely to wait until the second and third trimesters (4).

According to Ethiopian Demographic and Health Survey, 2005 , only $6 \%$ of women make their first ANC visit before the fourth month of pregnancy. The median duration of pregnancy for the first ANC visit is 5.6 months (4.2 and 6.0 months for urban and rural women respectively). In urban settings where the health services are physically accessible and ANC at the governmental health facilities is provided free of pay, only $32.4 \%$ of mothers seek the service before 16 weeks of gestation and $30.1 \%$ of pregnant mothers did not attend the service at all. The figure for rural women is much worse than this (5).

Utilization of health services is a complex behavioral phenomenon. Empirical studies of preventive and curative services have often found out that use of health services is related to the availability, quality and cost of services, in addition to social structure, health beliefs and personal characteristics of the users $(7,8)$.

The reviewed literatures reported that, sociodemographic variables like maternal age, marital status, maternal education, occupation, ethnicity, religion, family income, residence, accessibility of service; obstetrics history like parity and mother's undesired child birth outcome; past experience of service like previous service utilization, perceived quality of service, cost of the service; awareness of care and pregnancy related complications; and other factors like influence of husband, wanted or unwanted pregnancy, unrecognized symptoms of pregnancy, and fear of parents were found to be predictors that either positively or negatively influence timing of ANC booking (8-15).

According to Anderson and Newman Socio-behavioral model which was used to conceptualize this study, individual's access to and use of health services is considered to be a function of three characteristics. These are predisposing factors (the socio cultural characteristics of individuals that exist prior to their need of health service), enabling factors (the logistical aspects of obtaining care) and need factors (the most immediate cause of health service use, from functional and health problems that generate the need for health care services) (Figure 1).

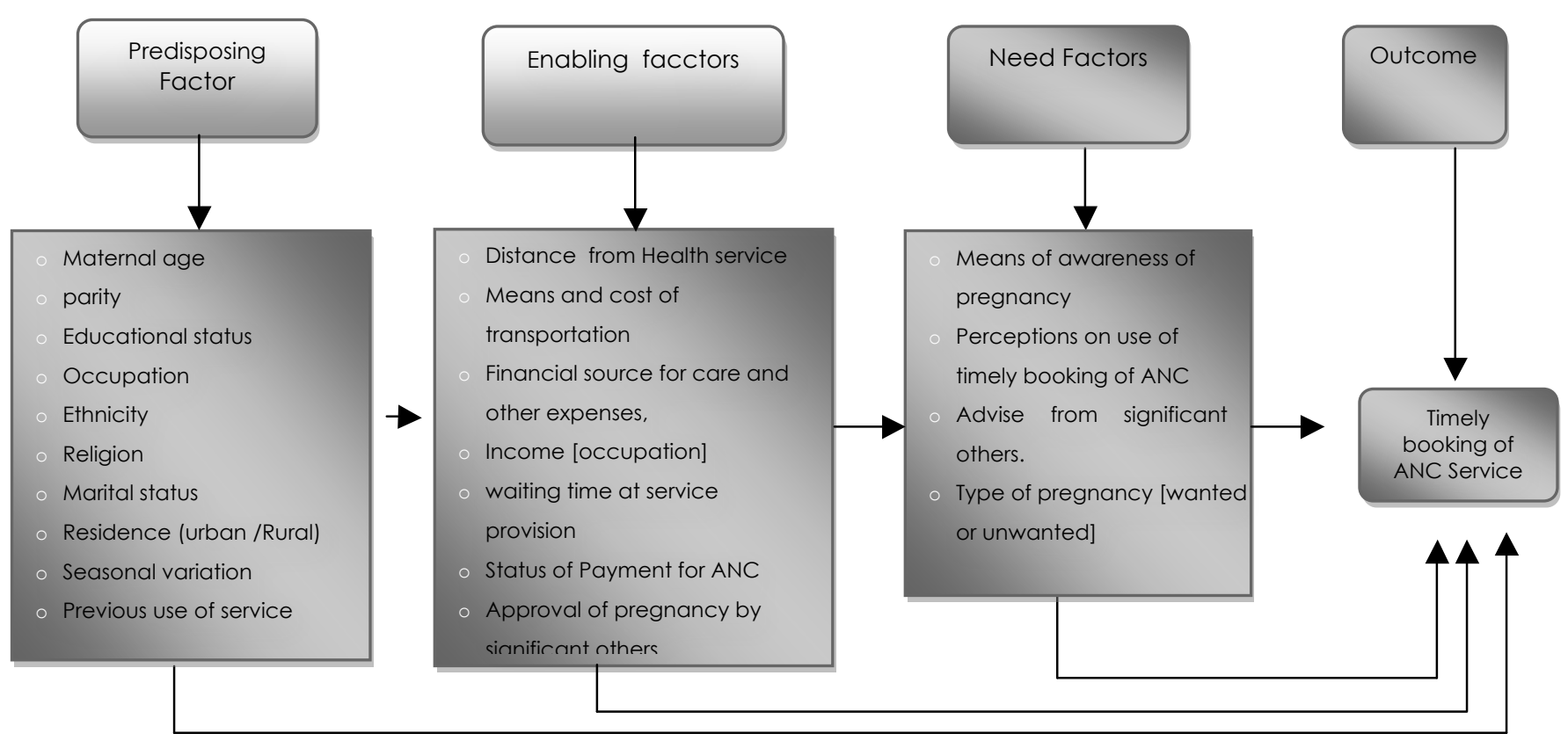

Figure 1: Conceptual framework for timely use of ANC (Adapted from Anderson 1995)

Quality of care is evaluated in the light of the provider's technical standards and patients/client expectations. Provision of quality ANC service has a great importance in improving maternal and child health. One of important aspects of ANC is seeking of the service timely by service utilizers and provision of appropriate services according to the recommendations by service providers. Therefore, identifying factors in areas where mothers present to ANC too late during pregnancy where the services are accessible physically and financially is important to inform service providers and program 
implementers so that it improves the quality of the service.

The aim of this study was to answer the following basic research questions: Why pregnant women delay to attend ANC? Does previous use of antenatal care influence timely booking of antenatal care? Which factor predominately influences timely booking of the service?

\section{Methods}

Facility based cross sectional study was conducted from March, 1 to 30, 2008. Data was collected from 630 pregnant women who were attending ANC service at 10 public health centers in Addis Ababa, Ethiopia, using pretested and pre-coded structured questionnaires.

The sample size was calculated using single population proportion based on the following assumptions. Since there is no prevalence specific to Addis Ababa on timing of first ANC visit, a prevalence of $50 \%$ was taken to estimate the sample size. A 95\% confidence interval and margin of sampling error tolerable was assumed to be (4\%). The non-response rate of $5 \%$ was added to the sample.

Ten health centers one from each sub city was selected based on their client flow. In case where equal client flow are existing one health center was selected using a simple random sampling method. Health center facilities were preferred because they are the first level of care facilities and mainly engaged in preventive health services. The sample size was assigned to each health center equally (63 per health center).

At selected health facilities, study subjects were recruited for the study at ANC service when they appear to begin the service or return for ANC follow-up. All the cases that were willing to participate during the study period were taken until the required sample size was obtained.

For triangulation of finding from quantitative data, twenty respondents two from each facility who booked too late were purposely selected for in-depth interview using semi-structured questionnaire. Ten service providers one from each facility were interviewed indepth to assess their service provision pattern. Data were collected using trained female nurses who were not from the same facility. Data collectors interviewed pregnant women waiting after they completed their daily visits. The purpose of data collection and importance of the study as well as the significance of true information were enlightened to the participants in order to maximize the respondent rate and to generate reliable data.

Before conducting the study, ethical clearance was obtained before conducting the research from Addis
Ababa University Faculty of Medicine School of Public Health and Addis Ababa City Administration Health Bureau. Permission was obtained from respective subcity health department and health facilities. Willingness to participate in the study and written consent was obtained before data collection at private setting around the ANC unit from study subjects. Only those appeared willing to participate were included in the study.

Quantitative data analysis was done using SPSS (Statistical Package for Social Sciences) version 15 for windows. A two step (bivariate and multivariate) logistic regression was performed to identify significant predictors. Test of level of significance was evaluated at $5 \%$.

The qualitative data generated from lately booked pregnant women and service providers were collected using semi-structured interview guide. The data were transcribed and summarized under the main thematic areas manually.

\section{Results}

A total number of 612 pregnant women appeared for service to the facilities and 9 service providers were interviewed, Out of the 630 pregnant women considered for interview, $612(97.1 \%)$ responded. The median age of respondents was 25 years, and the age ranges from 17 to 40 years. Eighty five percent $(85 \%)$ of the respondents were married. Most respondents have reached Primary $(39.5 \%)$ and Secondary (32.4\%) school levels (Table 1).

All the nine service providers were female nurses with Diploma educational background. The duration that they served in the unit ranges from one and half year to six years. Only one $(11 \%)$ of the service provider was with midwifery background.

The proportion of respondents who made their first ANC visit within the recommended time (before or at 12 weeks of gestation) is $246(40.2 \%)$ while those who booked late (after 12 weeks of gestation) were 366 (59.8\%). The timing of first ANC booking ranges from $1^{\text {st }}$ month to $9^{\text {th }}$ months of gestation. The mean timing was 4 months $(\mathrm{SD}=1.8)$ (Figure 2).

Among 275 respondents who gave history of previous pregnancy, $254(92.4 \%)$ reported that they have had experience of ANC for the pregnancy preceding the current while the rest $21(7.6 \%)$ did not have past ANC experiences. Two hundred twenty two $(87.4 \%)$ of the respondents who had past experience of ANC utilization reported that they remember the gestational time when they booked ANC for pregnancy preceding the current. 
Table 1: Socio-Demographic characteristics of respondents by time of booking, Addis Ababa, 2008

\begin{tabular}{|c|c|c|c|}
\hline \multirow[t]{2}{*}{ Variable } & $\begin{array}{l}\text { Booked within time (12 weeks } \\
\text { of gestation and before }\end{array}$ & $\begin{array}{l}\text { Booked late (after } 12 \\
\text { weeks of gestation) }\end{array}$ & Total \\
\hline & Number (\%) & Number (\%) & Number (\%) \\
\hline \multicolumn{4}{|l|}{ Age in years $(n=612)$} \\
\hline $15-19$ & $17(2.8)$ & $42(6.9)$ & $59(9.6)$ \\
\hline $20-24$ & $101(16.5)$ & $122(19.9)$ & $223(36.4)$ \\
\hline $25-29$ & $83(13.6)$ & $134(21.9)$ & $218(35.5)$ \\
\hline $30-34$ & $31(5.1)$ & $44(7.2)$ & $75(12.3)$ \\
\hline $35-39$ & $13(2.1)$ & $22(3.6)$ & $35(5.7)$ \\
\hline $40-45$ & $1(0.2)$ & $2(0.3)$ & $3(0.5)$ \\
\hline \multicolumn{4}{|l|}{ Ethnicity $(n=612)$} \\
\hline Amahara & $108(17.6)$ & $142(23.2)$ & $250(40.8)$ \\
\hline Oromo & $51(8.3)$ & $67(10.9)$ & $118(19.3)$ \\
\hline Guragie & $57(9.3)$ & $108(17.6)$ & $165(27.0)$ \\
\hline Tigre & $16(2.6)$ & $22(3.6)$ & $38(6.2)$ \\
\hline Silte & $8(1.3)$ & $15(2.5)$ & $23(3.8)$ \\
\hline Others & $6(1.0)$ & $12(2.0)$ & $18(2.9)$ \\
\hline \multicolumn{4}{|l|}{ Religion ( $n=612)$} \\
\hline Orthodox & $174(28.4)$ & $254(41.5)$ & $428(69.9)$ \\
\hline Muslim & $51(8.3)$ & $93(15.2)$ & $144(23.5)$ \\
\hline Protestant & $20(3.3)$ & $17(2.8)$ & $37(6.0)$ \\
\hline Catholic & $1(0.2)$ & $2(0.3)$ & $3(0.5)$ \\
\hline \multicolumn{4}{|l|}{ Marital status $(n=612)$} \\
\hline Single (not married) & $12(2.0)$ & $15(2.5)$ & $27(4.4)$ \\
\hline Married and live together currently & $208(34.0)$ & $313(51.1)$ & $521(85.1)$ \\
\hline Cohabitation & $23(3.8)$ & $34(5.6)$ & $57(9.3)$ \\
\hline $\begin{array}{l}\text { Ever married but separated or } \\
\text { Widowed }\end{array}$ & $3(0.5)$ & $4(0.7)$ & $7(1.1)$ \\
\hline \multicolumn{4}{|l|}{$\begin{array}{l}\text { Educational level (Grade completed) } \\
(n=612)\end{array}$} \\
\hline Illiterate (can not read \& write) & $33(5.4)$ & $65(10.6)$ & $98(16.0)$ \\
\hline Illiterate (can read and write) & $14(2.3)$ & $23(3.8)$ & $37(6.0)$ \\
\hline Primary $(1-8)$ & $91(14.9)$ & $151(24.7)$ & $242(39.5)$ \\
\hline Secondary $(9-12)$ & $90(14.7)$ & $108(17.6)$ & $198(32.4)$ \\
\hline Diploma and Above & $18(2.9)$ & $19(3.1)$ & $37(6.0)$ \\
\hline \multicolumn{4}{|l|}{ Occupation $(n=612)$} \\
\hline Employed (wedge) & $98(16.0)$ & $124(20.3)$ & $222(36.3)$ \\
\hline House wife & $138(22.4)$ & $230(37.6)$ & $367(60.0)$ \\
\hline Others & $11(1.8)$ & $12(2.0)$ & $23(3.8)$ \\
\hline \multicolumn{4}{|l|}{$\begin{array}{l}\text { Household income per month } \\
(n=519)\end{array}$} \\
\hline Less than 400.00 ETB (below Q1) & $70(13.5)$ & $94(18.1)$ & $164(31.6)$ \\
\hline 400 - 1000 ETB (Q1-Q3) & $103(19.8)$ & $153(29.5)$ & $256(49.3)$ \\
\hline Above 1000 ETB (Grater than Q3) & $45(8.7)$ & $54(10.4)$ & $99(19.1)$ \\
\hline Total & $246(40.2)$ & $366(59.8)$ & $612(100)$ \\
\hline
\end{tabular}

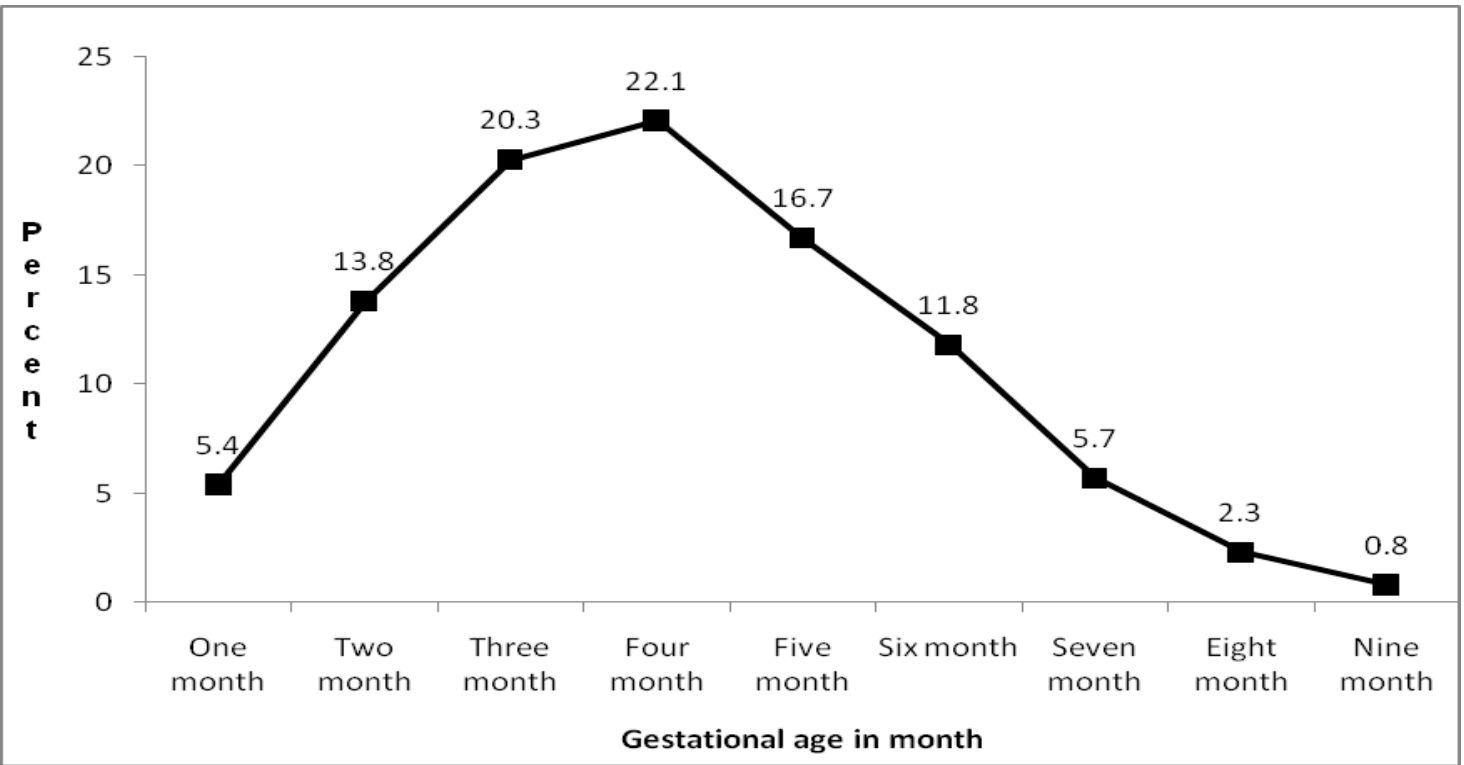

Figure 2: Percentage of pregnant women by gestational age in month during ANC booking, Addis Ababa, 2008 
Bivariate analysis showed that respondents those who received information and advise on correct time of booking, who perceived that the correct time of ANC booking is within 12 weeks of gestation, appear with first pregnancy, those with planned pregnancy, who confirmed their pregnancy by medical checkup and with secondary school and above were more likely to book first ANC within recommended time compared to others $(\mathrm{OR}=12.07,95 \%$ CI $5.58,26.11),(\mathrm{OR}=3.23,95 \% \mathrm{CI}$ $2.02,5.14),(\mathrm{OR}=2.28,95 \%$ CI $1.62,3.19),(\mathrm{OR}=1.80$, $95 \%$ CI $1.28,2.54),(\mathrm{OR}=1.56,95 \% \mathrm{CI} 1.12,2.16)$ and $(\mathrm{OR}=1.47,95 \%$ CI $1.06,2.05)$ respectively (Table 2$)$.
The multivariate analysis revealed that respondents who received advice on correct time of booking, who said their pregnancy was planned and appear with first pregnancy, were more likely to book within recommended time compared to others $(\mathrm{AOR}=10.10$, 95\% CI: 4.54, 22.40); (AOR=1.87, 95\% CI:1.11, 3.23); $(\mathrm{AOR}=1.86,95 \% \mathrm{CI}: 1.01,3.44)$ respectively (Table 2$)$.

The major reasons given by respondents for late booking were perceived correct time, inappropriate advice by providers, time constraints, unplanned pregnancy, unaware of pregnancy, negligence and others by 119 $(33 \%), 65(18 \%), 56(15 \%), 49(13 \%), 42(11 \%), 22$ $(6 \%)$ and $13(4 \%)$ respectively (Figure 3$)$.

Table 2: Association of Factors with timely booking of first ANC, Addis Ababa, 2008

\begin{tabular}{|c|c|c|c|c|}
\hline \multirow[t]{2}{*}{ Variable } & \multicolumn{2}{|c|}{ Time at first visit } & \multirow[t]{2}{*}{ Crude OR (95\%Cl) } & \multirow{2}{*}{$\begin{array}{l}\text { Adjusted OR } \\
\text { AOR }(95 \% \mathrm{Cl})\end{array}$} \\
\hline & Booked timely & Booked late & & \\
\hline \multicolumn{5}{|l|}{ Education level } \\
\hline Primary and Below & $138(22.5)$ & $239(39.0)$ & 1 & 1 \\
\hline Secondary and above & $108(17.6)$ & $127(20.9)$ & $1.47(1.01,2.05)^{*}$ & $1.02(0.66,1.87)$ \\
\hline \multicolumn{5}{|l|}{ Parity } \\
\hline No parity & $168(27.4)$ & $178(51.5)$ & $2.28(1.62,3.19)^{\star *}$ & $1.86(1.01,3.44)^{*}$ \\
\hline Parity one and above & $78(29.1)$ & $188(30.7)$ & & 1 \\
\hline \multicolumn{5}{|l|}{ Means of conforming pregnancy } \\
\hline By urine test & $138(22.5)$ & $165(27.0)$ & $1.56(1.12,2.16)^{*}$ & $1.21(0.72,2.02)$ \\
\hline By other means & $108(17.6)$ & $201(32.8)$ & & 1 \\
\hline \multicolumn{5}{|l|}{ Knowledge of time of booking } \\
\hline Perceived before 12 weeks & $220(35.9)$ & $265(43.3)$ & $3.23(2.02,5.14)^{\star *}$ & $1.50(0.72,3.11)$ \\
\hline Perceived after 12 weeks & $26(4.2)$ & $101(16.7)$ & 1 & 1 \\
\hline \multicolumn{5}{|l|}{ Type of Pregnancy } \\
\hline Planned & $173(28.3)$ & $208(34.0)$ & $1.80(1.28-2.54)^{*}$ & $1.87(1.11,3.23)^{*}$ \\
\hline Unplanned & $73(11.9)$ & $158(25.8)$ & 1 & 1 \\
\hline \multicolumn{5}{|l|}{ Advised when to book first ANC } \\
\hline $\begin{array}{l}\text { Advised to book before } 3 \text { months of } \\
\text { Gestation }\end{array}$ & $117(37.4)$ & $103(32.9)$ & $12.07(5.58-26.11)^{\star *}$ & $10.10(4.54,22.40)^{\star *}$ \\
\hline $\begin{array}{l}\text { Advised to book after } 3 \text { months of } \\
\text { Gestation }\end{array}$ & $8(2.6)$ & $85(27.2)$ & 1 & 1 \\
\hline \multicolumn{5}{|l|}{$\begin{array}{l}\text { Past experience of timing for } \\
\text { pregnancy preceding the current }\end{array}$} \\
\hline Booked within 3 months & $47(21.2)$ & $53(23.8)$ & $1.40(0.91,2.15)$ & \\
\hline Booked after 3 months & $22(9.9)$ & $100(45.0)$ & 1 & \\
\hline
\end{tabular}
${ }^{\star} p<0.05 ; \quad{ }^{* *} p<0.001$

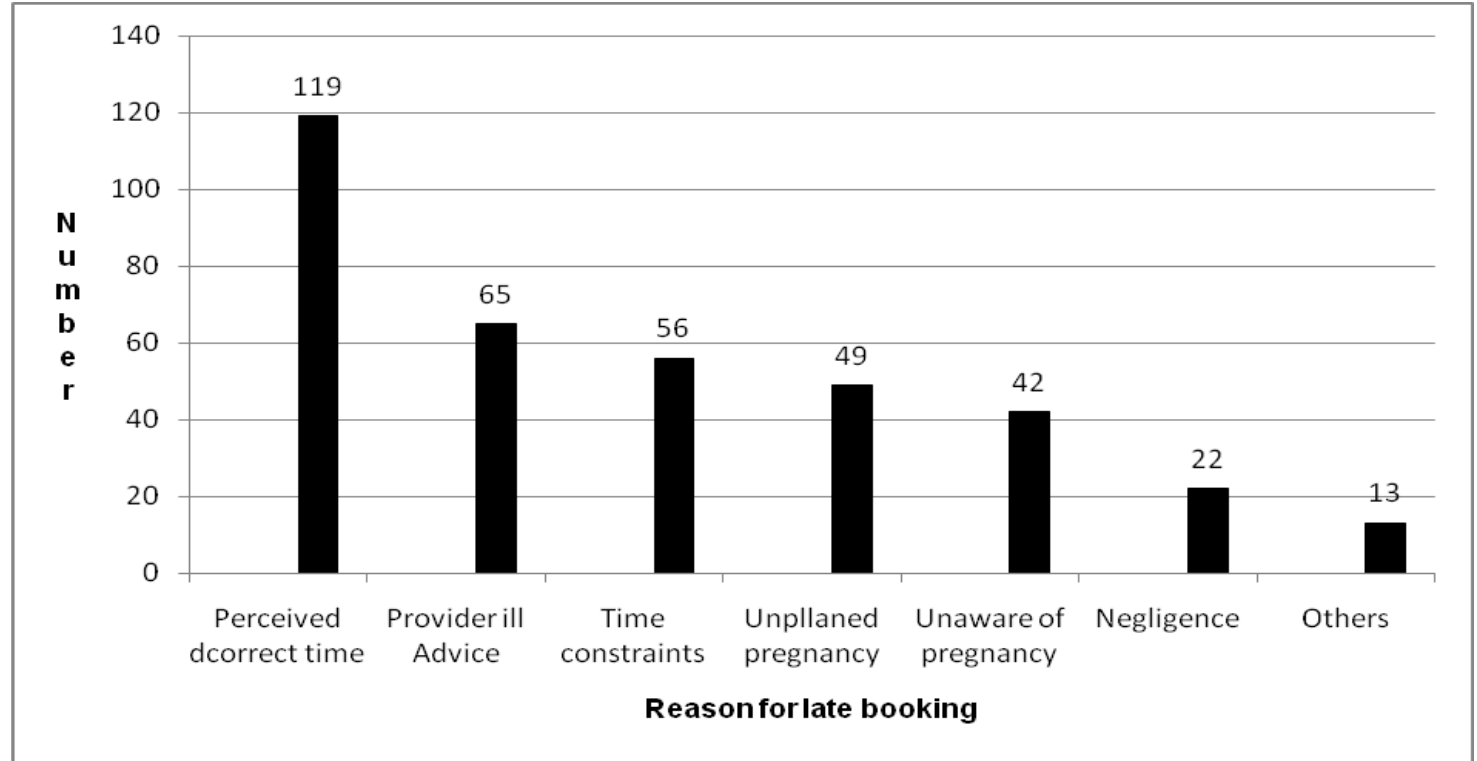

Figure 3: Number of Respondents by reason for late booking of ANC, Addis Ababa, 2008. 
During the in-depth interview, respondents who were too late to seek care reported different reasons. The major reasons stated were due to appointment that the health care provider made in the previous pregnancy which was mainly after four months.

"...I attended ANC for the past two pregnancies. I experienced that when I came early as soon as I missed my menstrual period, the health workers appointed me to come back after five months of gestation. But I don't know why? I got this advice two times. That is why I came at my sixth months of gestation" [A 29 years old, married, parity two, who booked her first visit at 6 months of gestation].

Almost all service providers included in qualitative interview reported that neither specific training addressed nor guideline provided as source of information to providers so far on issues of timing of ANC. The services that have been provided to pregnant women who booked early (before 12 weeks of gestation) were urine test to confirm pregnancy and providing appointment after 18 weeks of gestation. Only one provider reported that HIV testing is also recommended after urine test is done.

"...I have been providing ANC based on the knowledge I learned during my basic training. If the pregnant women came too early before 4 months of gestation, we will confirm pregnancy by urine test and appoint her to come back after 18 weeks of gestation. This appointment time is preferred as it is the time to listen to fetal heart beat. We don't have any guideline or training to provide better service" (A nurse who have been working at health center for the past 7 years and assigned at ANC two years ago").

\section{Discussion}

According to this study, only about one-third of respondents started their ANC within the recommended time and the rest (two-third) booked late. The mean gestational age at which the pregnant women booked the first ANC was found $4 \pm 1.8$ months. The timing of ANC who booked within recommended time is low compared to the ANC coverage in Addis Ababa. This finding also suggests that, physical and financial accessibility of the service alone cannot ensure proper utilization of available service.

The proportion of respondents who have had their first visit within recommended time in the preceding pregnancy was $45 \%$, while only $31 \%$ of these pregnant women who have had booked ANC within recommended time were booked within recommended time in the current visit. The difference is statistically significant at 95\%. This finding indicated that, pregnant women with past experience of ANC service utilization did not demonstrate timely booking of the service. This indicates that pregnant women were not informed about the appropriate time of booking or the information might be misleading. This finding is also in harmony with by findings from qualitative data which confirms that, service providers advise pregnant women to come for the service follow-up after they complete four month when they booked in the first trimester.

In this study, it was found that respondents who were informed to book within 12 weeks of gestation were more likely to book within the recommended time. This finding is similar with the study conducted in Nigeria which suggests that pregnant women who were advised by physicians were booked timely (14). This suggested that proper information and advice on pattern of ANC utilization from service providers are important to book timely. On the other hand, had it been the service providers inform and advise the pregnant women when to book ANC service, past service utilization could have been one of the positive predictors for timely booking of ANC.

In this study, pregnant women with planned pregnancy were found to be more likely booking ANC within the recommended time compared to respondents with unplanned pregnancy. This finding is quite in line with the study done in South Africa which stated that unintended pregnancy is a factor for delays in seeking ANC (14). It is believed that, wanted pregnancies are more cared by the women and other significant individuals, which enables the women to book timely for ANC.

The finding of this study reveled that as parity increases the experience of timely booking decreases. Respondents with first pregnancy were about two times more likely to be booked for ANC within the recommended time compared to respondents with parity one and above. This finding is similar with studies done in Nigeria and Mozambique as well as Addis Ababa (5, 14, 19-21). This could be explained as pregnant women with first pregnancy might have more desire to confirm pregnancy and perceive severity of the outcome of pregnancies compared to multi-parous women which may contribute to their booking early. This is one of the opportunities that most vulnerable group of pregnant women for undesired out come of pregnancy can be reached easily and encouraged for future ANC utilization.

\section{Conclusions and recommendations}

Majority of the mothers did not practice timely booking of first ANC though the services are physically accessible and are being provided free of cost. Information provided to pregnant women on timing of the first booking and follow-up visits were not clear and not encouraging mothers to book timely. That is why pervious ANC utilization is not a positive predictor for timely booking. This is a very important missed opportunity.

Clear information and advice on timely booking, appearing with first pregnancy, and planned pregnancy 
were found to be the most statistically significant factors for timely booking of ANC.

The reasons for late booking were reported as previous experience, provider ill advice, time constraints, unplanned pregnancy, unawareness of the pregnancy and negligence.

Therefore, physical and financial accessibility alone cannot assure effective service utilization of ANC. The need for proper information and advice on timely booking from service providers and community level and/or health facility is very important for the effective utilization of the service.

As per the findings of this study, the authors recommend that focused ANC should be strengthened in all health facilities; providers should be given appropriate training and supportive supervision, importance of timely booking should be stressed during community education programs, and in order to improve the quality of ANC provision, clear service delivery guidelines should be avail.

\section{Limitations of the study}

On data collection, due to fear of memory lapse on timing of all previous timing of ANC utilizations, only ANC use and timing for pregnancy preceded the current was asked. It would have been better if the effect of the length of the pregnancy interval between this latest pregnancy and the previous pregnancy was controlled to see the effect of previous utilization of ANC on current booking of ANC.

\section{Acknowledgements}

We are grateful to the pregnant women who participated in this study; School of Public Health, Addis Ababa University; Addis Ababa City Administration Health Bureau and Alkan University College.

\section{References}

1. Banta D. What is the efficacy/effectiveness of antenatal care and the financial and organizational implications? WHO Regional Office for Europe Copenhagen. Health Evidence Network report 2003. Available from: URL:http:/www.euro.who.int, accessed as of October 2007).

2. Villar J, Bergsjø P. New WHO antenatal care model: Randomized trial. World Health Organization. Geneva: WHO; 2002.

3. Allen D, Ammann A, Bailey $\mathrm{H}$, et al. Revised Recommendation for HIV screening of Pregnant women prenatal counseling and guidelines consultation. 2001;50(RR19):59-86. Available from; URL: http://www.mmwrq@cdc.gov, accessed as of september 2007).

4. Carla A, Tessa W, Blanc A, Van P, et al. ANC in developing countries, promises, achievements and missed opportunities; an analysis of trends, levels and differentials, 1990-2001. WHO Geneva, 2003.
5. Central Statistical Authority, ORC. MACRO. Ethiopia Demographic and Health Survey 2005. Addis Ababa; Maryland; 2006.

6. Chakraborty N, Islam MA, Chowdhury RI, Bari W, Akhter HH. Determinants of the use of maternal health services in rural Bangladesh. Health promotion International 2003;18(4):327-337.

7. Pamela L, Paterson J, Wouldes T, et al. Factors affecting ANC attendance by mothers of Pacific infants living in New Zealand. The New Zealand Medical Journal 2005;118:1216-1489.

8. Andersen RM. Revisiting the behavioral model and access to medical care: does it matter? J Health Soc Behav 1995; 36(March):1-10. [Abstract].

9. Institute of medicine. Prenatal Care: Reaching Mothers, Reaching Infants. National Academy press, 1988. Available from: URL: http://books.nap.edu/catalog/731.html, accessed as of October 2007).

10. Chandiok N, Dhillon B.S, Kambo I, et al. Determinanats of ANC utilization in rural areas of India, 2006, J Obstet Gynecol India January/February; 2006;56(1):47-52.

11. Mekonnen Y. Mekonnen A. Utilization of maternal health care services in Ethiopia. ORC Macro Maryland U.S.A, 2002. Available from: URL: http:// www.measuredhs.com, accessed as of October 2007).

12. Abrahams N. Jewkes R. Study of health care seeking practice of pregnant women in Cape Town. CERSA women's health, medical research council; South Africa: Cape Town: 1998.

13. Lee SH, Grubbs LM. Pregnant teenagers' reasons for seeking or delaying ANC. Clinical nurse Research 1995;4(1):38-49.

14. Okunlola MA, Ayinde OA, Owonikoko KM, Omigbodun AO. Factors influencing gestational age at ANC booking at the university college hospital, Ibadan, Nigeria 2006, Journal of Obstetrics and Gynecology 2006;26(3):195-7.

15. National Cancer Institute, Theory at a Glance, A guide for Health Promotion Practice, United State Department of Health and Human Service, National Institute of Health, 2005.

16. Abrahams N, Jewkes R, Mvo Z. Health care seeking practice of pregnant women and the role of midwifes in Cape Town. Journal of midwifery and Women Health South Africa 2001(July to August);46(4);240-247.

17. Gharoro EP, Igbafe AA. ANC: Some characteristics of the booking visit in a major teaching hospital in the developing world. Med Science Monitor 2000;6(3):519-522.

18. Magadi MA, Madise NJ, Rodrigues RN. Variation in antenatal care between women of different communities in Kenya. African Population and Health Research, Population Council; 1999. 
19. Fantahun M. Factors Affecting ANC attendance and preference of place of delivery by pregnant women in Gulele District, Addis Ababa. [Masters Thesis]: Addis Ababa University: School of Public Health; 1992.

20. Mekonnen Y. Pattern of maternal care service utilization in southern Ethiopia. Evidence from a community and family survey. Ethiop $J$ Health Dev 2003;17(1):27-33.

21. Adamu YM, Salihu HM. Barriers to the use of ANC and obstetric care service in rural Kano, Nigeria. Journal of Obstetrics and Gynecology 2002:600603. 